\title{
Arbor
}

\section{La «pérdida de España»: monarquía, reinos y naciones}

\section{José Manuel Pérez-Prendes Muñoz-Arraco}

Arbor CLXI, 633 (Septiembre 1998), 41-58 pp.

Don José Manuel Pérez-Prendes nos transmite sus reflesiones sobre un problema que nos es acuciante: la "pérdida de España" ayer y hoy. La comparación la establece en función de las creencias religiosas y de las constitucionales, como principios vertebradores de la única paz social posible en cada época. Jugar con la construcción-desconstrucción de la vida política, tema grave, sobre todo si tenemos presente que ha habido anhelos históricos de España ganadas y de España rotas.

El objetivo de estas páginas no es otro que contribuir a estimular la reflexión acerca del modelo estatal hoy dibujado en virtud de la Constitución de 1978, y situar esa indagación a la luz de lo que la investigación histórica realizada pueda revelarnos sobre la práctica de gobierno de Felipe II.

A nadie se le oculta que en ambos ámbitos históricos se proyectó una conjunción jurídico-política de formas estatales distintas, articuladas bajo una soberanía común. También es perceptible que la referencia a un tópico historigráfico muy antiguo, "la pérdida de España", puede ser referida, aunque de modos muy diversos a las dos experiencias vitales citadas de nuestro país y en esas apelaciones subyace la cuestión básica de como se concibe esa España, que según unos puede ser "perdida", pero que por relación asociativa, también puede ser "ganada".

Tendremos pues que manejar, el lector y yo, un hilo conductor que nos explicite los motivos por los cuales no considero (ya lo anticipo) 
demasiado válidas las imágenes sobre la acción política deFelipe II, suministradas por la historiografía distinta de Rafael Altamira, Helmut Königsberger, Fernand Braudel y Fernández Álvarez. Pero como se verá no se trata de un recuento de datos para clasificarlos en aceptables o no en unas páginas eruditas. Intentaré sólo señalar la causa que a mi juicio invalida más o menos, mucha de la investigación realizada fuera de la de estos cuatro autores.

En un segundo paso habrá que situar la historia acarreada y las imágenes políticas sobre la idea de España que formaron el horizonte intelectual de la vida pública, cuando Felipe II tomó el timón de la monarquía hispana. Es lo que intentaré expresar con la dicotomía, "pérdida"-"ganancia" aplicada al concepto de España. Desde ahi, estas páginas se cerraran con algunas consideraciones, sobre los puntos que considero principales para, desde la práctica de gobierno felipina, transitar a posibilidades de aplicación de la Constitución de 1978.

La construcción y destrucción de modelos de convivencia política y la revisión crítica de los existentes, se ha revelado como uno de los grandes vectores en los acontecimientos de la segunda mitad del siglo XX. Entre la tolerancia y la crueldad, el viejo recinto europeo se ha visto afectado por esos procesos desde España hasta la fenecida Unión Soviética y desde Irlanda hasta Italia. Incluso al lado de su propio y cultisimo corazón, en las tierras del antiguo Imperio austro-húngaro la ferocidad más abyecta ha sido vecina en los pueblos de Yugoslavia, de la elegante racionalidad de checos y eslovacos.

¿Sirve de algo en ese ambiente, considerar las demandas y los logros políticos del tiempo de Felipe II? ¿Que valor conservan algunas de las interpretaciones más difundidas de entre las generadas por los historiadores que trabajaron en ese tema?

Pienso que a la primera pregunta corresponde una respuesta afirmativa, pero para comenzar a apoyar ese criterio, debo opinar antes acerca de la segunda.

En general, muchas de las investigaciones históricas sobre ese monarca más vulgarizadas en España, en tiempos decimonónicos y en las primeras décadas del siglo XX, parecen sumamente debilitadas en nuestros días. El motivo no es tanto una vejez de las técnicas empleadas, cuanto la muy intensa subordinación de los autores a una polemización sobre sus propios valores. Con ella empaparon, queriendolo o no, los frutos de sus estudios.

La cosa venía, en su raíz, desde muy lejos. Nadie ignora que se ha combatido mucho por lograr una adjetivación adecuada para la realidad biológica del hombre. Animal, desde luego; pero ¿político? ¿ra- 
La "pérdida de España»: monarquía, reinos y naciones

cional? ¿nacional? ¿ladino?... La banal utopía de sustitución de calificaciones, ha sido plancton para debates científicos que la suficiencia de sus protagonistas cometió el exceso de exhibir como importantes. Pues el hombre es todo eso, y algo más aún, no algo de eso y lo es simultáneamente. Lo es para sí y para la convivencia. En la contemplación y juicio de ese convivir-en-el-tiempo, es donde el historiador se sitúa. Introducido ahí a la fuerza y para su contaminación, sin poder enajenarse para su salvaguardia, asume esa complejidad sólo a través de la práctica de sí mismo, aunque no se entere casi nunca de ello. Por eso todo historiador dice que hace historia, pero sólo hace historiografía y más la hace, cuanto mas se resiste a confesarlo. Aceptemos pues hablar algo de historiografía.

Felipe II, fue un excelente objeto historiográfico. Lo es y lo será también en cuanto que muchos de los historiadores y ensayistas interesados en su persona, obra o contexto, han relatado la particular visión del mundo que ellos poseían, tomando como pretexto lo que el Austria hizo o dejó de hacer.

Ranke le situó como el paralelo mediterráneo occidental del Sultán turco, para equilibrar así el triángulo que venía enseñoreado por el vértice central y elevado en el que colocaba la presencia tudesca. Para Marañon, se trataba de un débil con poder. Sánchez-Albornoz no vaciló en concebirlo como el fracasado gestor económico de una política quijotesca heredada y agravada. Menéndez y Pelayo, le apreció como héroe y aún mártir de expedientes y de gabinete. Menéndez Pidal le vio, más celoso que los teólogos, contradecirse en su mecenazgo cultural con un cerrar puertas y ventanas a las Universidades. Ortega y Gasset dibujó para el monarca un perfil de soberbia diabólica culminado en la ejecución de El Escorial. Madariaga lo retrató de mediocre, desconfiado y beato, ante el brillo político de su padre y el ideal religioso de sus bisabuelos.

La lista de juicios como esos podría alargarse hasta el tedio más desconcertante. Los tópicos de «demonio del Mediodía», «brazo de Trento» y otros de igual pasión correlativa son bien conocidos de cualquier persona medianamente culta.

Es cierto que los autores aludidos matizaron y a veces mucho en sus exposiciones, especialmente Menéndez y Pelayo, esos juicios que suenan a latigazos o a aclamación. Pero no lo es menos que lo aquí resumido forma el nervio central del criterio que a cada uno corresponde. Es ahí, en esa instantánea, que no puede ser calificada de falsa, donde se advierte como cada escritor, está descubriendo su adjetivación del hombre, a través de Felipe II en clave de instrumento para la referencia. 
Hay que asumir que esa transustanciación de los valores del biógrafo al biografiado es lo que se nos presenta como historia.

Eso resulta agudamente valido hoy, cuando ya no se puede, después de Altamira, Königsberger, Braudel, etc., seguir alegando, como sí podía decir Menéndez y Pelayo, que Felipe II aún no había encontrado un historiador de enjundia satisfactoria hablando en general. Altamira arrostró la impopularidad de enjuiciarle en clave de hombre de Estado (yo me atreví a seguirle por ese camino), Braudel dio el gran paso de señalar que Felipe II, sólo puede ser entendido como articulador político de grandes espacios, en éste caso el Mediterraneo y con ello abrió además el camino a la consideración de la huella de su actividad en el área atlántica y en la del Pacifico. Kamen ha desecho infinidad de tópicos erróneos y juicios precipitados, favorables o desfavorables. Poco empaña la gran calidad general de su labor que, en algún tema concreto, pero importante, se haya dejado llevar del peso de opiniones reiteradas, pero no válidas, como ocurre con el juicio de Pidal o Kagan sobre la cuestión de la Universidiad, que resulta heredado por Kamen a través quizá del segundo. Quizá haya que buscar un mayor equilibrio entre la visión algo "rosada" de Kamen y la demasiado preocupada por agredir de María José Rodriguez Salgado.

Se me dirá que, aun aceptando la tesis según la cual toda historia no es sino historiografía, opinión que muchos no tolerarán, no estamos con Felipe II a presencia de un hecho diferencial, pues idéntico juicio de valor podría proponerse para cualquier otro caso de investigación histórica.

Así es, desde luego, en la sustancia de las cosas pero de ningún modo en su significación. Mi hipótesis es que el caso de Felipe II constituye, con los de Julio Cesar, Carlomagno y Napoléon al menos, la mejor posibilidad de reconstruir la existencia de un plano conceptual de lo político que ha emergido en algunos momentos de la Historia. Tuvieron todos ellos la pretensión de atalayar supratemporalmente la articulación de las comunidades políticas en estructuras más amplias de lo que permiten los tejidos ensoñadores de los nacionalismos o las técnicas jurídicas de las estatalizaciones. Dicho de otro modo, se tensionaron hacia el ensanche posible del adjetivo "político" aplicado al "animal» hombre, contribuyendo a albergar en esa ampliación y sin que estallase, su contradicción en cuanto "animal nacional»-«animal racional», bien conceptualizada hoy por Walker Connor.

En aquellos momentos de la Historia en que se hizo palpable ese movimiento tendencional, se favoreció que resultase algo más angosto e innecesario el triste refugio de "animal ladino" dibujado 
La "pérdida de España»: monarquía, reinos y naciones

por Nicolás Ramiro Rico, como escapatoria a Hobbes, más que como consecuencia.

Para contribuir a precisar, ya en nuestro segundo paso, el mundo político que gobernó Felipe II, podemos partir del sintagma «la pérdida de España", de estirpe medieval en los textos de nuestra cronistica desde el siglo VIII, como resumió García de Valdeavellano. Una relación asociativa elemental, nos lleva a sugerir "la ganancia de España», lo que, desde otra perspectiva, se llama "la pérdida».

Cuando aquellos textos hablan de "pérdida", todos sabemos que significa deplorar la fragmentación política peninsular acaecida por el teatral hundimiento de la monarquía visigoda. Aunque en esta se han detectado desde la Historia jurídica sobre todo, tendencias centrífugas a las que, con giro orteguiano, se ha denominado por Rafael Gibert "particularismos», no es idea menos verdadera y sí más significativa en la imagen global, heredada, reelaborada y transmitida desde el siglo VIII, a partir de la labor iniciada por los muzárabes cultos, la de una consolidación con Leovigildo, Sisebuto y Suínthila (586-631) de un poder político único para todo el ámbito peninsular, hecho que encontraría su elogio y glosa en la «Historia de los reyes godos" concluida por San Isidoro en 625-626.

En realidad esos reyes y éste cronista recuperaban una antigua percepción extrapeninsular. Desde hacia muchos siglos, por grandes que fuesen las diferencias entre las gentes asentadas en la Península ibérica, se las apreciaba desde fuera como conjunto coherente. En esto estuvieron conformes griegos, como Estrabón, Diodoro, Polibio o Apiano o romanos como César, Livio, o Plinio. Por su lado, la muy pragmática administración romana concibió paralelamente una Hispania que estaba - más lejos o más cerca, que crecía y era "nova" con Caracalla y que se agrupaba como una "diócesis» en el Bajo Imperio, desde Marruecos incluso. No es muy difícil percibir aquí que el plural «Hispaniae» nace, mas que de diferencias internas, de las peculiaridades que marcaba, en el tiempo y en el espacio, su comunicación con Roma. Tampoco proceden de otro modo, ni el veronés Catulo, ni el celtíbero Marcial cuando escriben desde Roma sobre personas, o lugares hispanos. Esa pauta es también la de Orosio o Prudencio, etc.

Así pues los cronistas del siglo VIII, deploraban la ruptura de una unidad política penínsular a la que llaman España, que los visigodos habían extendido, actuando desde dentro, como los romanos habían hecho, incluso con Baleares, gobernando desde fuera. Tal caso ya no volvería a ocurrir hasta Felipe II en 1580 y se desvanecería otra vez en 1640 . 
En el horizonte intelectual de éstos cronistas, como en el de Desclot o Luis de Camoens, los pueblos situados en ese espacio, son parte de una España rota, aunque no sean iguales entre sí. Es la fórmula que, hacia 1444 recuperaba Juan de Mena, siguiendo de plano la tradición romana, incluso en la mención del norte marroquí.

«Vi las provincias de España en Poniente,

la de Tarragona, la de Celtiberia,

la nueva Cartago que fue la de Esperia,

con los rincones de todo Occidente

mostrose Vandalia la bien paresçiente,

e toda la tierra de la Lusitania,

la brava Galicia, con la Tingitania

donde se cría feroce la gente».

"Perdida de España", es pues equivalente en ese uso a hablar de fragmentación política del territorio también politicamente reunido. Una primera lucha para la "ganancia de España" pretendió la recomposición unitaria de un mosaico dispersado. Estudiar esos empeños ha inspirado unas líneas de acción historiográfica que, con notoria ligereza no se han estimado luego en su conjunto ni en sus diferencias, todo lo que cabía esperar. Se han alegado o se han combatido con demasiados oportunismos.

La primera puede centrarse en Ramón Menéndez Pidal (1947) y Diego Catalán (1982), en torno al texto del primero "Los españoles en la historia" que no puede leerse con plenitud, prescindiendo del segundo. Soportada en sólida documentación, esta línea señala que, desde el cordobés Al-Razi, la morada y no la sangre, marca la "ipseidad" de los españoles, dotados de un ensamblaje distintivo de sobriedadidealidad-individualismo. Vivido en exceso ese conjunto, la exorbitancia llevó históricamente a demasías, ya unitarias, ya regionalistas, y al problema de "las dos Españas». Aprecia esta interpretación un punto significativo de equilibrio vivido en días de los Reyes Católicos, gracias a un gobierno más atento al mérito y a la capacidad que a otras variables, en la promoción de gobernantes.

Desde 1954, Américo Castro insistió en la huella perdurable judeo-islámica, inmersa secularmente en las sociedades peninsulares de tal modo que, ni expulsiones ni conversiones habrían disminuido su impacto. No es la noción de "España" lo que ahí se niega. Se afirma, que el origen, ser y existir de los españoles no continúa como venía de tiempos romanos ni visigodos, sino cambia su perfil con la «rápida islamización de la gente hispano-romano-goda". Se somete a crítica 
el rasgo individualista. Pero insisto en recordar que afirma la existencia de España.

Por fin Claudio Sánchez-Albornoz, desde 1956 y con su «España un enigma histórico", enfrentado irremisiblemente a Castro, reivindicó la continuidad de lo español, en la sucesión temporal de prehistoria, romanidad, goticismo y castellanismo medieval y moderno. El aglutinante religioso habría sido, el catolicismo desde Recaredo (589) y el político, el eje leonés-castellano. Su conjunto sería la argamasa definidora de esa Historia.

Desde mi punto de vista y aun aceptando muchísimas ideas de Albornoz, que no es ahora adecuado inventariar, creo que aciertan tanto R.B. Tate, como Diego Catalán, al señalar que es el siglo XV y en la obra de Alfonso García de Cartagena o de Santa María, en su "Anacephaleosis» donde el mito de "lo gótico" se injerta en la imagen histórica de Castilla, para transformar a esta en la España continuadora del reino único con sede en Toledo. Más matizada era, en el mismo tiempo, la visión de Juan de Mena, como se ha visto.

En efecto, desde la información histórico-jurídica cabe asociar al juicio de esos dos investigadores que la obra recopilatoria de la legislación visigótica, el "Liber iudiciorum», pervivió desde el 711 más como referencia sociopolítica genérica que otra cosa, en Galicia, León y Cataluña, pero no en Castilla, que simbolizó su independencia en la quema pública y oficial de ejemplares de esa ley, oponiendo al "mito del Libro", otro mito, el del "país sin leyes", cuna de un Derecho libre y diferente. Se abrirían así dos contenidos políticos distintos para el término "España", el pancastellanista y su negación. Si desajustado era el primero, la segunda no resultó poco enloquecida.

Lo fue sobre todo porque ya en ultima instancia, y tras la Nueva Planta de Felipe V, los nacionalismos desarrollados desde 1898 en la Península (si el término viene de 1739 y 1830, no gana uso amplio sino después de 1898) aceptaron en realidad la tesis de una España pancastellana al presentarse como recuperadores de naciones distintas.

La radicalidad mayor correspondió al "aranismo" o doctrina de $\mathrm{Sa}$ bino Arana, base conceptual común a todos los grupos políticos nacionalistas vascos, que, entre sus muchas falsificaciones y mutilaciones introdujo la calificación de "extranjero" para lo "español", saltando sin más sobre las realidades evidentes del amplio papel engendrador de Castilla desempeñado por los vascones en muchas ocasiones y su inserción vital en la configuración política y religiosa de la monarquía hispana en la Edad Moderna. Efectos del desarrollo pormenorizado de ese planteamiento, es que hoy (cosa nada infrecuente) se empiece 
por generalizar a una amplia geografía, cruzada secularmente por flujos demográficos como el camino de Santiago, los rasgos antropológicos detectables a veces en necrópolis concretas y se acabe por llamar "mal vasco" a Ignacio de Loyola, entre decenas de proposiciones educativas semejantes.

La búsqueda de fragmentos interpretables de modo análogo en los textos históricos, se ha convertido en un ejercicio de apedreamiento, entre los defensores del sesgamiento de García de Santa María que heredó Sánchez-Albornoz y los reductores de la idea de "España" a una mera forma jurídica estatal a la que sólo se ve como limitadora del autogobierno de naciones diferentes entre sí.

No es posible aquí iniciar una enfadosa enumeración de citas y sus correspondientes discusiones exegeticas, pero sí es útil valorar en general el maximalismo tremendista que ha surgido frente a la no menos agobiante reducción de lo español a lo castellano. Fue rechazada ésta como ajena y no sin razón por muchos, mas movidos por la resistencia a su explotación política que por discrepancias técnicas con Menéndez Pidal, Sánchez-Albornoz, etc. Como testimonio generacional (reitero que todos hacemos historiografía) tengo el recuerdo de los universitarios que entendíamos a Raimon, en sus versos:

"T'adones, company,

que fa ja molts anys

que ens amaguen la historia

i es diuen que no en tenim:

que la nostra es la d'ells?»

A ciertas personas puede parecerles frívola esta cita. Pero yo no lo creo así, por lo que luego recordare decía el gravísimo Menéndez y Pelayo. Importa ahora que, si por aquel entonces yo escribía para mis alumnos de Historia del Derecho español, que para su estudio existía la necesidad metodológica «de descomponer España en Españas particulares", hoy se hace difícil soportar simplezas como las escritas en un periódico de ámbito nacional por un diputado gallego que diferencia a Galicia de España diciendo entre otros errores que aquella tiene su fundamento en el reino suevo y ésta en el visigodo, cuando desde el historiador gallego del siglo pasado, Antonio López Ferreiro, cualquier principiante sabe que Galicia conservó el símbolo del "Liber iudiciorum» gótico mientras que Castilla lo buscaba para quemarlo. Abunda demasiado éste tipo de culturilla, con acarreo de deformaciones.

No debo en éste ensayo seguir detallando la correntera de contradicciones, verdades y errores que se ha formado hasta hoy, no solo 
La "pérdida de España»: monarquía, reinos y naciones

hoy, con el concepto de España. Mi objetivo es solo relacionar la idea de "España" que recibe Felipe II y lo que hizo con ella en su modelo político.

Se ha insistido en que su padre el Emperador había concebido una partición de espacios para los dominios ciertos o previsibles de los Habsburgos. En ella el sector Países Bajos, Inglaterra, Escocia, Irlanda habría recibido como reyes a Felipe II y María Tudor, mientras que el Imperio romano-germánico se encabezaría por el hermano de Carlos V. Los reinos y provincias hispánicos habrían quedado para los descendientes de Felipe II y María de Portugal, desde el príncipe Carlos. Sólo en alguna parcial medida se cumpliría ese proyecto, pero aún así y todo Felipe II hubo de gobernar un conjunto de territorios numerosos y distintos. ¿Cómo los vertebró?

La propuesta que recibe nos muestra la prevalencia del concepto de España, a tono con las ideas de García de Cartagena. Se concibe a Castilla como el reino superior que gobernaba a los demás de la monarquía integrándolas con ello en una España, en la que se diluyen ante el protagonismo castellano. Juan de Padilla, en 1521, había escrito refiriéndose a la conjunción de reinos bajo los Reyes Católicos:

"con los invictos y bravos leoneses

el águila junto a los fuertes bastones

en él Castilla mostrando tal saña

que teme lo resto del reyno de España”

Ahí las alusiones a León, Aragón («los fuertes bastones») y el papel de Castilla, vertebradora por la fuerza del conjunto, "España" es evidente.

Por otro lado la unificación jurídica y religiosa era también un objetivo palpable en el mismo ambiente. A fines del siglo XVI, Bernardo de Balbuena, el Ariosto de nuestra épica idealista, esgrimía en «El Bernardo" como objetivo político la llegada de:

«el día que España a hierro y fuego meta

la grave carga que ahora le hace guerra

y de una Ley y un Dios haga su tierra».

A su vez Hernando de Acuña había planteado esa unificación a Carlos I como tarea de su tiempo:

«ya se acerca Señor o ya es llegada

la Edad gloriosa en que proclama el cielo

un pastor y una grey sola en el suelo,

por suerte a nuestros tiempos reservada" 
Y Andrés Rey de Artieda, no vaciló en señalar que Felipe II, acumulaba los reinos en que era posible esa labor:

«Este es Felipe, en número Segundo

primero entre los príncipes más grandes

pues que dar puedes una vuelta al mundo

como toda su costa y reino andes.

De las Molucas manda el Nuevo Mundo

y volviendo para el norte es suyo Flandes.

Junto al estrecho de Hercules: España

y de ahí, lo que el mar Tirreno baña

Felipe lo posee todo junto,

estando Letras y Armas en su punto".

Tomás López Medel, el oidor enviado a Centroamérica, no vaciló en exigir la unidad lingüística, destruyendo cualquier idioma indígena americano, en el menor tiempo posible.

Unificación política (Acuña), jurídica y religiosa (Balbuena), limgüística (López Medel) castellanocentrismo por la fuerza (Padilla), configuran un resultado, "reyno de España" (Padilla) que es propuesto al monarca para ser aplicado en la acumulación nunca vista de territorios que tiene bajo su cetro (Artieda). Debe completarse esta idea, recordando que la meta de unificación politica no es un rasgo original castellano. Para todo el Sacro Romano Germánico Imperio lo había reclamado el jurista italiano autor de las "Quaestiones de iuris subtilitatibus" pidiendo "que sea uno el Derecho, como uno es el Imperio" y la misma intención había sido traída a la Península por Jaime I de Aragón para estamparla inequívocamente en los Furs valencianos. Se trata pues de la recepción castellana (Nebrija) de un tópico jurídico europeo.

No deben rechazarse los testimonios de fuentes literarias si se rastrea un modelo estatal, pensando que debe buscarse sólo en textos más técnico-jurídicos. Ya Menendez Pelayo, a propósito de la imagen política de Felipe II, señaló que cuando el arte se apodera de estos temas acaba por adjudicarles una configuración socialmente prevalecedora.

Pero no es sólo el ambiente, la cuestión de la base doctrinal que podía justificar o condenar ese poder, resultaba también tema preocupante en el entorno felipino. Juan Gines de Sepúlveda, cronista regio desde los años del Emperador, no vaciló en escribir y enviarle un texto en tres partes, "De Regno" en el que conectando la ciencia política con la antigüedad clásica y la práctica de gobierno de ambos reyes, 
La "pérdida de España»: monarquía, reinos y naciones

señalaba a Felipe la reducción de todo gobierno a las dos formas de, política "ejercida sobre hombres libres para bien de éstos" y despótica, aplicada "sobre esclavos para provecho del que manda". Otra cosa sería y no es nuestro tema ahora, que su aristotelismo exacerbado le permitiese salir con bien de la propuesta elegida por él.

La sugerencia que Felipe II recibe es clara. Debe construir una España católica, universal y ultramarina, donde los reinos ingresados se adapten a la dominación castellana y debe gobernar el conjunto orientándolo a logros benéficos. Se le pide que asuma las ideas de García de Cartagena, lo que habría venido a ser hacer lo mismo que hará más tarde Felipe V, con la Nueva Planta, aunque éste, se inspirase en otra fuente, la experiencia francesa y no en sacar conclusiones prácticas de la ideología de la "Anacephaleosis».

Sin embargo, la práctica de gobierno de Felipe II, que es la que revela su modelo de Estado mejor que cualquier alarde moralizante perdido aquí o allá, como frase suelta, se parece sólo un poco a esas demandas.

Usando el camino británico de la reiteración de pautas y no el continental de la fijación instantánea de principios escritos, Felipe II aplicó una concepción constitucionalizadora de la vida pública, basandose en dos niveles. Uno, de incorporación paralela de comunidades políticas. Otro, de articulación con ellas, para una actuación política interna y externa. En realidad el Conde-Duque de Olivares, con su "Unión de Armas" sólo intentó acelerar y ampliar éste último plano y por eso pertenece "genéticamente", diríamos, a ésta línea y no es propiamente antecedente de la de los Decretos de Nueva Planta que sí se proponen cambiar los mecanismos asumiendo, además de una modernización necesaria, una castellanización impolítica. Corregir esa interpretación dada a la Unión de Armas, es un debate que habrá de arrostrarse algún día.

En el primer nivel, es claro que el monarca no eligió, como haría Felipe V, la fusión de sus reinos en uno. Sabido es que hubo sugerencias de modificar su titulación regia, simplificando con la mención «rey de España" la larga lista de dignidades que acompañaba a su nombre, ordenadas protocolariamente por calidad de título y antigüedad en su incorporación a la Monarquía. Pero no se hizo así, e incluso en las menciones más breves, como las impuestas por la escasez de espacio en la acuñación o la garantía documental de los sellos regios, Felipe II usa plurales, o añade a la mención de uno u otro reino (según al que se dirija la acción que la pieza recoge) la referencia "utriusque", ya suficientemente reveladora de sus criterios al respecto. Cuando se trata de actos legislativos 
o administrativos, donde el texto puede desenvolverse sin cortapisas, la enumeración detallada es la norma seguida constantemente. Tampoco optó por la fusión lingüística, salvo en el envenenado caso de los moriscos. Generó así algo muy parecido a lo que desea implantar en nuestro tiempo la "Carta europea de lenguas regionales».

Cada espacio conservó su personalidad jurídico-política, por más que la enormidad comparativa del esfuerzo económico del bloque LeónCastilla-Indias, haya desviado la percepción jurídica a causa del peso económico.

Bien advierte la intención de equilibrar en lo jurídico, la tarea recopilatoria y de modernización del conjunto de cada legislación peculiar. Así ocurre en Castilla y León en 1567 con la "Nueva Recopilación" que en realidad es la primera oficial de ellos, después de la de Alonso Díaz de Montalvo, que permaneció como privada, o de proyectos no publicados, como el generado en la Chancillería vallisoletana, hacia 1480. También Portugal en 1583 inició la revisión y puesta al día de sus compilaciones anteriores que culminaría en el nacimiento de las "Ordenaçoes Filipinas". Los Países Bajos, precisamente bajo el Duque de Alba, entre 1569 y 1579 verán acelerarse esa tarea, cuyos primeros pasos eran perceptibles desde 1531. En Cataluña se realiza análoga tarea en 1587 como segunda recopilación del Derecho territorial. Por fin ningún familiarizado con la historia americana puede desconocer que Felipe II fue mano principal en la configuración del Derecho indiano, que había de crearse como propio de las nuevas tierras, hasta que se pudiese recopilar en 1680 .

Se comprueba así que en cada reino y territorio se gobernó conforme a sus leyes, conservadas, recopiladas o promulgadas para unos u otros, dentro de lo que era mecánica general establecida históricamente para la actuación legislativa en cada uno. Y a eso hay que añadir el funcionamiento habitual de las instituciones político-administrativas y judiciales que se ajustó a la misma fórmula en cada sitio.

Nada más lejos pues de la realidad que un imaginario triunfo del "decisionismo castellano» que, como se ha escrito, igualaba los reinos al modelo legislativo e institucional castellano-leonés. Las inevitables decisiones (ya dije alguna vez que gobernar es decidir) eran válidas en principio sólo en cada reino, no extrapoladas de unos a otros ni homogeneizadas sobre el rasero de uno sólo, como ciertos ambientes pedían al rey según se ha visto. En este primer nivel, parece pues claro que los hechos diferenciales (oníricos o ciertos) entre reinos tuvieron un continuado eco constitucionalizante bajo la práctica del gobierno por Felipe II. 
La "pérdida de España»: monarquía, reinos y naciones

Pero es en la segunda dimensión de su modelo, lo que he denominado «nivel de articulación" donde quizá pueda extraerse más de alguna consideración válida todavía hoy.

Parece evidente que una mera yuxtaposición de reinos ni crea ni facilita un proceso de armonización política entre ellos. Si se quiere obtener ésta es preciso operar de forma que las autonomías se articulen entre sí, tendencia que de suyo no reside en ellas. Lo que naturalmente les es más propio es precisar lo que hay de amorfo en su esencia con la configuración de pasos hacia la independencia, justificada en un signo nacionalista.

Pero existe una íntima e inevitable perversidad en todo modelo político nacionalista. Es inspirarse en criterios de distinción respecto del que se define, tácita o expresamente, como "el otro", el que es visto como ajeno y a partir de ahí comienza a ser objeto de exclusión, lo que es el inicio del no respeto como una previsible escalada discriminatoria.

Puede atenuarse esa tendencia si se toma como diferenciadora la «naturaleza» (residencia, en definitiva) y no la "natio» que lleva de suyo a pensar o a ejecutar limpiezas étnicas.

Los factores no racionales, emocionalizados, ensoñadores, estéticos, etc. que Walker Connor ha señalado como distintivos del «etnonacionalismo" llevan inevitablemente a que no haya diferencias entre tal concepto y el de "nacionalismo". La adición o no de violencia a estos movimientos, puede perjudicar (a veces es al contrario) su imagen social, pero no cambiar su esencia, lo mismo que un adjetivo no transforma un sustantivo, sino que lo delimita.

Dada la resistencia histórica de estas actitudes, no parece generar mejora una reacción contradictoria. Mejor es modelar una función antidespótica para las personas, e integradora para las comunidades, acomodándolas en bloques políticos amplios que acerquen mosaicos de tribus a sociedades políticamente integradas. La enormidad geográfica de los dominios de Felipe II, replanteó a su medida esta cuestión, que ya se había presentado a los ojos de Cesar y Carlomagno y volvería de nuevo a empezar ante Napoleón.

Es muy conocido que para la acción general de gobierno de su variopinta monarquía, Felipe II consolidó y potenció instituciones unipersonales o colegiadas de justicia y administración comunes a todos los reinos, que ya venían siendo aplicadas de antes. Se consolidó así, pese a tensiones esporádicas, un fluido fáctico de solidaridad de los reinos en la acción política. Obliga hoy a mucho el esfuerzo de una categoría, el "consenso constitucional», cuyos mínimos contenidos y eventuales desarrollos, coherentes y analógicos, se han convertido en la 
España de 1998, por la lógica de las fuerzas en presencia, en la bestia negra de los nacionalismos.

En todo caso es de destacar aquí y ahora que la eficacia del gobierno de Felipe II en esta dimensión de fomento de una solidaridad política interregional, contó con mucha mayor intensidad, sinceridad y espontaneidad que la ahora existente. Jugaba mucho más la iniciativa para esa actitud, por parte de los reinos, que su imposición por parte de la monarquía.

Esta logró subrayar el propio y tradicional papel de Rey-juez; los Consejos relativos a materias de Estado, Guerra o Hacienda, como órganos supremos de resolución, conforme al principio de interrelación, no de división de poderes; los Secretarios; la incorporación de estas tareas de oriundos de cualesquiera reinos, lo que no impedía que en oficios mas locales o regionales (del plano anterior en fin) se proveyesen los nombramientos con naturales, aunque no siempre, como es sabido, etc. Ya sólo por eso resulta desajustada la equiparación de Ranke, entre ésta Monarquía y el Imperio turco. Aparece en cambio como categoría más aplicable a toda la monarquía, la noción de «unión real» que Victor Ferro ha apreciado en la Corona aragonesa.

Pero quizá lo más interesante y perdurable de su práctica constitucionalizante, resida en el todavía hoy poco explorado, pero evidente, sistema de principios inspiradores de aglutinación de reinos autónomos y en los pasos dados hacia ciertas garantías de las personas, pues crisis vividas en su reinado, especialmente la del quinto Juan de Lanuza, Justicia Mayor de Aragón en 1591, necesitan ser reestudiadas a la luz de estas posibilidades y de las exigencias, supuestas o reales de la seguridad del Estado. En todo caso más allá de las dimensiones técnicas fueristas.

En una rápida ampliación de todo esto debo aludir como básica, a la decisión de señalar valores como principios y ejes del ordenamiento jurídico de la Monarquía y a la subsiguiente voluntad de protegerlos institucionalmente en todos los reinos y para todos los sujetos integrantes de ella mediante acciones homogéneas ya de gobierno, ya de justicia. Desde luego que Felipe II, no fue inventor de ninguna de esas ideas, pero sí radicalizó su uso político. Me estoy fijando en la religión católica. La conjunción entre religión y poder le vino heredada en gran medida, aunque desde los estudios de Fernández de los Ríos y de Reinhold Schneider sabemos cuanto la maximalizó.

Los valores superiores que inspiran un ordenamiento jurídico son imprescindibles. Son su diseño primero y decisivo. Ciertamente hoy nadie razonable escogería ninguna religión para adjudicarle esa fun- 
ción, lo cual no es desconocer el peso histórico que han tenido en la formación de valores sociales. Pero la función, digamos el "sitio", tiene que existir, aunque lo alojado en él no pueda ser hoy lo que Felipe II colocó allí. En cambio si nos sirven en nuestro hoy, considerar la fuerza y la coherencia con las que ese rey ejecutó y midió cada acción de gobierno para realizarla como efecto de los principios esenciales inspiradores del sistema.

Dicho de otro modo, puede aprender de éste monarca, cualquier gobierno actual español, que la libertad, justicia, igualdad y pluralismo político, señalados en el articulo 1,1, de la Constitución como valores superiores del ordenamiento jurídico de España, son referencias obligatorias de rutina diaria, para valorar hasta su más mínima decisión y ha de hacerlo con la misma fuerza que Felipe II revisaba las suyas a la luz del predominio social excluyente que atribuyó a la religión católica.

En realidad, España, como concepto jurídico-político, es sólo esa conjunción de valores. Podrá ser la lengua la "sangre del espíritu" como quiere Unamuno, aunque para mí se agota en instrumento de comunicación y de estética abierto a todos, pero entiendo que la sangre de la voluntad política, reside en sentirse circulado por esas ideas-valor. "La distinción de Connor entre "patriotismo" como lealtad al Estado y "nacionalismo" o lealtad a la nación, permite entender que el patriotismo constitucional existe y es primordial como quiere Habermas. La esencia de lo nacionalista, tal como arriba señalé, encierra genes antagónicos con esos valores y su dinámica tiende a conservar o a engrosar aquellos, pero no a corregirlos.

Importa además considerar la existencia, en el nivel de articulación constitucionalizante practicado por Felipe II, de tres piezas destinadas a mantener la vivencia política en el respeto y uso de los valores superiores del ordenamiento. Me refiero a la Inquisición, los recursos de fuerza y a la cuestión, nada anecdótica, de la capitalidad estatal.

Referirme a la primera es hacerlo a la historia de un pernicioso fracaso, pese a la critica que -puede generar ese juicio en algunos. Desde hace años me he apartado en publicaciones que todos pueden leer, de los historiadores actuales que, un poco al modo de Menéndez y Pelayo defienden o disculpan con argumentos cuantitativos, tan monstruosa y perversa institución. Es más, no me es problemático avanzar en el rechazo, señalando que algunos metíficos rasgos del sistema procesal penal de hoy, como los secretos sumariales arbitrariamente usados o el fomento de las acusaciones hechas por supuestos "arrepentidos", vienen en ultima instancia a revivir las taimadas técnicas inquisitoriales 
de la acusación ocultada por los jueces al denunciado o la protección y halago a los delatores.

Ciertamente hay muy poco, casi nada de jurídicamente ni éticamente rescatable hoy de las acciones del Santo Oficio. Sólo cabe quizá una reflexión sobre ella. Se la quiso para monopolizar estatalmente la acción institucional aseguradora de la vivencia social de los valores inspiradores del sistema. Sus lastres conceptuales y los métodos aplicados culminaron en atribuir a una institución antisocial la iniciativa y capacidad única de vigilar la forma en que entidades y personas, vivían o se apartaban de unos valores que además no debían ser impuestos por la fuerza. Pero por otro lado, no es lícito olvidar que hoy debe cuidarse, en cualquier parte, la aplicación del artículo 1,1 de la Constitución. Y ello en forma más ágil y de más amplia y mejor imagen social de lo que pueden tutelar el Defensor del pueblo o el Tribunal Constitucional, colocados «ex post factum» de los eventuales errores y pendientes de la iniciativa de parte.

Tan suprautonomicamente como Felipe II movió a la Suprema, en defensa de la religión impuesta como última meta de la vida pública, debe el Estado hoy coordinar, fomentar y suplir la acción de escuelas, partidos políticos, sindicatos, asociaciones y medios de información, en una tarea de impregnar y mantener en la conciencia general la necesidad de comportamientos acordes con el referido artículo constitucional (este sí, legitimado de abajo a arriba) sin dejar que se vacíe en una mera verbalidad o limitándose a actuaciones esporádicas y desconectadas. Es preciso diseñar y ejecutar una política de «empapamiento" social constitucional, por así decirlo, no crear una Inquisición para la democracia.

Si hablamos de garantías, aludamos a los recursos de fuerza. Con ellos y ante el necesario aforamiento que le vinculaba a los tribunales eclesiásticos, cualquier clérigo podía pedir al rey, si eran conculcadas por estos órganos las garantías a respetar, alzarse al Rey, para que «forzase" a los jueces eclesiásticos, si era preciso tanto, a dejarle intervenir en la resolución por medio de jueces regios. La canonistica tradicional presentó siempre éstas figuras como intromisiones de los reyes en la vida privativa de la Iglesia e incluso las disculpó a veces algún autor de esa línea viéndolas inspiradas en un fervor religioso excesivo, pero simpático en fin de cuentas.

No caben distorsiones mayores. Por encima de reinos y aún de la Iglesia, el monarca garantizaba a sus súbditos sometidos a Tribunales eclesiásticos su igualdad jurisdiccional con los restantes. Esa acción tutelar de derechos fundamentales es la que importa considerar desde 
La «pérdida de España»: monarquía, reinos y naciones

la perspectiva de estas reflexiones, para sacar consecuencias sobre las posibles y muy necesarias mejoras de eficacia en las funciones de Tribunal Constitucional, Fiscal general del Estado y Defensor del Pueblo, instituciones no sólo necesitadas de refuerzos particulares, sino quizá más aún de una ley orgánica común, coordinadora de las bases sobre las que desarrolle luego el ejercicio de sus competencias.

Queda por fin la cuestión de la capitalidad de España que Felipe II y el artículo 5 de la Constitución de 1978, fijan en Madrid. Que la decisión felipina influyó decisivamente en la vertebración política española, lo mostró en 1985 Alfredo Alvar y por haberlo meditado a la luz de su monografía, tengo muchas dudas acerca de que el mejor entendimiento de ese articulo, consista en configurar artificialmente a Madrid como otra Comunidad autónoma, para lo que carece de historia, ignorando la que si tiene, la de capitalidad. Se me dirá que con eso sería una demarcación con estatuto de distrito federal y la Constitución no tiene ese carácter federalista.. Uno de sus redactores, Gregorio Peces-Barba, ha alegado recientemente al rechazar el federalismo, que todo lo que es posible en esa línea ya está en su texto. De acuerdo, pero entonces ¿no cabe desarrollarlo?

No partió Felipe II, como ya he resumido, de un ambiente social propicio a su sistema de práctica constitucionalizante. No se ha valorado por eso el modo silencioso pero firme, con el que rehuyó la demanda castellanizadora en que insistían los partidarios de una concepción de España al modo de Alfonso García de Cartagena. Tal decisión vendría con los decretos de Nueva Planta y esa es otra historia. Pero también el hijo de Carlos I contaba con mucha más voluntad de colaboración en la idea de España de lo que hoy traslucen diversos entornos con fuerza social. Esa variante lleva a percibir que no es la consideración de Felipe II como gobernante, un erudito problema de precedentes históricos, sino de actitudes vitales perennes o truncadas. Para España, su rey Felipe II y su Constitución de 1978, son experiencias procedentes de sistemas jurídicos distintos, donde eventuales cuestiones de consonancia han de estimarse en talantes, para encontrar conexiones de sentido.

No podemos hoy acompañarle al rey en la selección de una religión como inspiradora exclusiva de un sistema constitucional, pero sí en la decisión de fijar con fuerza de Derecho unos valores a los que debe ajustarse todo ente (reinos, autonomías, etc.) dotado de competencias jurídico-públicas. Tampoco estaría de más revisar nuestro aparataje jurídico-político para lograr como él, pero por otros medios, un buen seguimiento de la vivencia de esos valores en las relaciones sociales, 
58

José Pérez-Prendes Muñoz-Arraco

educativas y políticas y en la curación de la angustia de muchos que (como los clérigos de la Edad Moderna no veían en su Iglesia) no ven practicar hoy, por el Estado, la fuerza jurídica necesaria para un "conocer" justo, dicho sea como entienden "conocimiento" los procesalistas. 